\title{
EFECTO DEL VERTIMIENTO DE SUBPRODUCTOS DEL BENEFICIO DE CACAO (Theobroma cacao L.) SOBRE ALGUNAS PROPIEDADES QUÍMICAS Y BIOLÓGICAS EN LOS SUELOS DE UNA FINCA CACAOTERA, MUNICIPIO DE YAGUARÁ (HUILA, COLOMBIA)*
}

\author{
Kely Lorena Ortiz-Valbuena ${ }^{1}$, Ricardo Álvarez-León ${ }^{2}$
}

\section{Resumen}

Objetivos: Determinar el efecto del vertimiento de los subproductos del beneficio de cacao en el suelo, de acuerdo a algunas propiedades químicas y biológicas en una finca cacaotera en el municipio de Yaguará del departamento del Huila. Alcance: Inventario químico cualitativo de los suelos colectados y caracterización con base en su análisis. Metodología: En este lugar se delimitó un área de $50 \mathrm{~m}^{2}$ para el depósito, teniendo en cuenta el emplear el nivel mínimo de manipulación de dos circunstancias concretas: presencia-ausencia, empleando una prueba de hipótesis con un grado de confiabilidad del 95\%. Los métodos de análisis para las propiedades físicas: $\mathrm{pH}$ (potenciométrico), y químicas: magnesio, potasio y calcio $\left(\mathrm{NH}_{4} \mathrm{OAc}-\mathrm{AA}\right)$, fósforo (Bray II), relaciones $\mathrm{Ca} / \mathrm{Mg}$ y $(\mathrm{Ca}+\mathrm{Mg}) / \mathrm{K}$ (por relaciones catiónicas), para las biológicas, como cuantificación de microorganismos fijadores de nitrógeno, bacterias, hongos, solubilizadores de fosfato (conteo en placa por siembra en superficie). Principales resultados: La variabilidad de los parámetros evaluados en el suelo está afectada por los vertimientos de exudados y las acumulaciones de cáscaras. Se presentó una notable variación de las propiedades evaluadas ( $\mathrm{pH}$, magnesio, potasio, calcio, fósforo, así como en la relación entre cationes, comportamiento que en este trabajo obedece al proceso de descomposición de los materiales orgánicos depositados en el suelo, rechazando la hipótesis nula para cada uno de los parámetros evaluados. El efecto del vertimiento de los subproductos del beneficio del cacao sobre los tres parámetros biológicos se evidencia en el efecto ocurrido, comprobando así la hipótesis formulada para cada uno de ellos. Respecto al parámetro de los hongos y las bacterias heterótrofas se evidenció que este grupo de microorganismos en T1-1 presentó un descenso poblacional que pudo haber sido producto de la escasa precipitación que se registró en la época seca. Conclusiones: No se encontró una relación directa concluyente que permitiera saber si son las cáscaras o el exudado lo que provoca la mayor variación, porque se asumieron en conjunto. Se pudo determinar que la variabilidad de los parámetros considerados en el suelo está afectada por los subproductos, y se proponen algunas estrategias para su manejo adecuado: empleo de las cáscaras para alimentación de animales, elaboración de pectinas o como abono, después de tratamiento adecuado en las composteras, asimismo el exudado para la elaboración de bebidas fermentadas o no, de néctares o como agente modificador del pH para suelos alcalinos.

Palabras clave: T. cacao, suelos, cáscara, exudado, microorganismos, Huila.

\footnotetext{
FR: 2-II-2015. FA: .30-IV-2015

${ }^{1}$ Magíster en Desarrollo Sostenible y Medio Ambiente. Universidad de Manizales. Neiva (Huila), Colombia. E-mail: kelylorena@gmail.com

${ }^{2}$ Magíster en Oceanografía Biológica y Pesquera. Manizales, Colombia. E-mail: ricardoalvarezleon@gmail.com 


\title{
EFFECT OF DUMPING OF BENEFIT PRODUCTS CACAO (Theobroma cacao L.) ON SOME CHEMICAL AND BIOLOGICAL PROPERTIES IN SOILS OF A COCOA FARM, CITY OF YAGUARA (HUILA, COLOMBIA)
}

\begin{abstract}
Objectives: To determine the effect of the dumping of the byproducts of the benefit of cocoa on the floor, according to some chemical and biological properties in a cocoa farm in the town of Yaguará of Huila. Scope: Qualitative chemical inventory of collected oils and characterization based on their analysis. Methodology: Presence-Absence, using a hypothesis test with a level of reliability of $95 \%$ in this place, an area of $50 \mathrm{~m}^{2}$ for the shell taking in to account the minimum level hiring handling two specific circumstances delineated. Analytical methods for physical properties: $\mathrm{pH}$ (potentiometric), and chemical: magnesium, potassium and calcium (NH4OAc-AA), phosphorus (Bray II), $\mathrm{Ca} / \mathrm{Mg}$ ratios and $(\mathrm{Ca}+\mathrm{Mg}) / \mathrm{K}$ (for relations cationic), for biological, and quantification of nitrogenfixing microorganisms, bacteria, fungi, solubilizing phosphate (plate counts by plating surface). Main results: The variability of the parameters evaluated in soil is affected by discharges of exudates and accumulations of shells. He was presented are mark able variation of the assessed properties $(\mathrm{pH}$, magnesium, potassium, calcium, phosphorus, as well as the relationship between cation behavior in this work, due to the decomposition of organic materials deposited on the ground, rejecting the null hypothesis for each of the parameters evaluated. Effect of the dumping of the by products of the benefits of cocoa three biological parameters, evidence on the effect ocurred thus proving the hypothesis formulated for each of them. Regarding parameter fungi and heterotrophic bacteria was evidenced that this group of microorganism in T1-1 presented a population decline that could have been the result of low rainfall recorded in the dry season. Conclusions: Conclusive direct relationship that would not know if they are found. Shells or exudate that causes the greatest variation, because they took together were able to determine that the variability of the parameters considered in the soil that is affected by products, and some strategies are proposed for proper management: use of shells for animal feed, processing or pectinase fertilizer, after proper treatment in composting, also the exudates to prepare fermented or not, nectars or $\mathrm{pH}$ modifying agent for alkaline soils drinks.
\end{abstract}

Key words: T. cacao, soil, shell, exudate, micro-organisms, Huila, Colombia. 


\section{INTRODUCCIÓN}

En Colombia, el cacao es uno de los productos que cuentan con ventajas comparativas derivadas de condiciones naturales para su producción, como las características del clima y de los suelos, y su carácter de sistema agroforestal que ayuda a conservar el medio ambiente (ESPINAL et al., 2005).

A raíz de la importancia económica del cacao para Colombia, el Gobierno nacional lo ha considerado como un producto con amplio potencial de mercado interno y externo; tanto así que la meta del Ministerio de Agricultura y Desarrollo Rural (MADR) para el año 2020 consiste en aumentar las áreas de siembra.

Consecuencia de lo anterior, en el sistema de producción de cacao se genera un gran volumen de residuos, que generalmente quedan acumulados en el cultivo, circunstancia que se ha traducido en serios problemas ambientales a nivel del suelo por acumulación de materiales conformándose un sustrato para la propagación de microorganismos patógenos al cultivo (MEDEIROS, 1977; PARRA, 1994); asimismo, las cáscaras partidas, debido a su forma cóncava, en épocas de lluvias son depósito de agua que facilitan la multiplicación de insectos, además son foco para la propagación de Phytophorora spp., causa principal de pérdidas económicas de la actividad cacaotera (LÓPEZ et al., 1984).

Con base en lo anterior, en el presente trabajo se establecerá el efecto del vertimiento de subproductos del beneficio de cacao sobre algunas propiedades químicas y biológicas en el suelo de una finca cacaotera, municipio de Yaguará (Huila). Lo anterior, con el fin de comprobar si este vertimiento en el suelo favorece o desfavorece algunas propiedades del mismo.

Características del cacao (Theobroma cacao L.). Es un arbusto de 2 a $3 \mathrm{~m}$ de altura, que crece en ambientes tropicales y pertenece a la familia Sterculiaceae. El fruto de cacao es de tamaño, forma y color variable, la pared es dura y gruesa. Las semillas de cacao están rodeadas por una pulpa aromática la cual procede de sus tegumentos. La pulpa mucilaginosa está compuesta por células esponjosas parenquimatosas, que contienen células de savia ricas en azúcares (10-13\%), pentosas (2-3\%), ácido cítrico (1-2\%) y sales (8-10\%). Durante el proceso de cosecha de las semillas de cacao, la pulpa es removida por fermentación e hidrolizada por microorganismos. La pulpa hidrolizada es conocida en la industria como "exudado". Durante la fermentación la pulpa provee el sustrato para varios microorganismos que son esenciales para el desarrollo de los precursores del sabor del chocolate, los cuales son expresados completamente después, durante el proceso de tostado. Aunque la pulpa es necesaria para la fermentación, a menudo hay más pulpa de la necesaria. El exceso de pulpa, que tiene un delicioso sabor tropical, ha sido usado para hacer los siguientes productos: jalea de cacao, alcohol y vinagre, nata y pulpa procesada (MEJÍA \& ARGÜELLO, 2000).

Composición del fruto de cacao. En la Figura 1 se aprecia que el fruto de cacao se compone por cáscaras, habas y placentas, que se obtienen cuando se quiebran los frutos al retirar los granos (NAVARRO \& MENDOZA, 2009). 


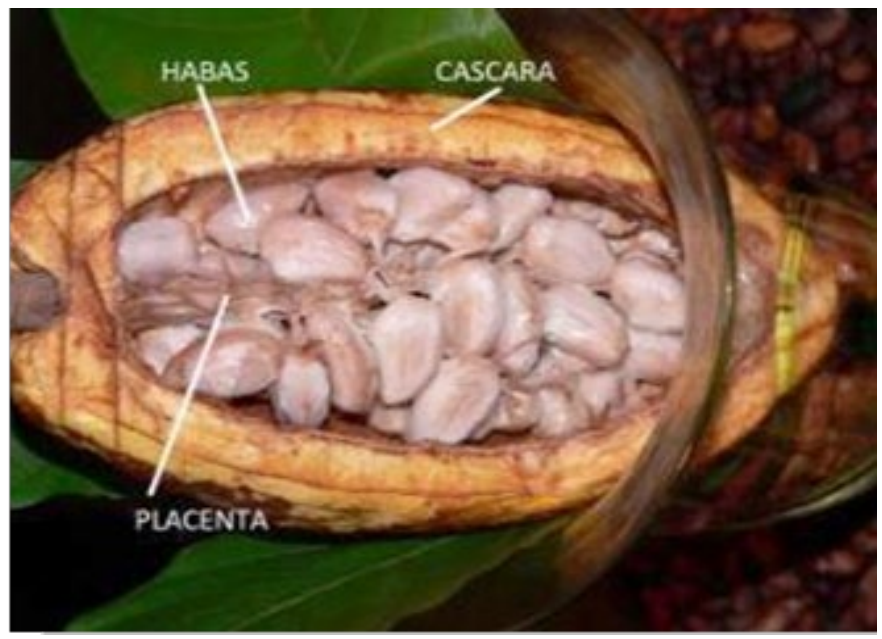

Figura 1. Composición del fruto de cacao. Según NAVARRO \& MENDOZA (2009).

En las tablas 1, 2 y 3 se presenta la composición química de las cáscaras de la mazorca de cacao, la composición química del grano de cacao y la composición química del mucílago de cacao respectivamente.

Tabla 1. Composición química de la cáscara de la mazorca de cacao. Según MEJÍA \& ARGÜELLO (2000).

\begin{tabular}{lc}
\hline \multicolumn{1}{c}{ Componente } & \% $\mathbf{p} / \mathbf{p}$ \\
\hline Humedad & 85 \\
Proteína & 1,07 \\
Minerales & 1,41 \\
Grasa & 0,02 \\
Fibra & 5,45 \\
Carbohidratos & 7,05 \\
N & 0,171 \\
P & 0,026 \\
K & 0,545 \\
Pectinas & 0,89 \\
\hline
\end{tabular}


Tabla 2. Composición química del grano de cacao. Según MEJÍA \& ARGÜELLO (2000).

\begin{tabular}{lc}
\hline \multicolumn{1}{l}{ Componente } & $\% \mathbf{p} / \mathbf{p}$ \\
\hline Manteca de cacao & 54 \\
Proteína & 11,5 \\
Ácidos orgánicos y aromas & 9,5 \\
Celulosa & 9 \\
Ácidos tánicos y color & 6 \\
Agua & 5 \\
Sales minerales & 2,6 \\
Teobromina & 1,2 \\
Azúcares & 1 \\
Cafeína & 0,2 \\
\hline
\end{tabular}

Tabla 3. Composición química del mucílago de cacao. Según MEJÍA \& ARGÜELLO (2000).

\begin{tabular}{lc}
\hline Componente & $\begin{array}{c}\text { \% p/p } \\
\text { (base húmeda) }\end{array}$ \\
\hline Agua & $79,2-84,2$ \\
Proteína & $0,09-0,11$ \\
Azúcares & $12,50-15,9$ \\
Glucosa & $11,6-15,32$ \\
Pectinas & $0,9-1,19$ \\
Ácido cítrico & $0,77-1,52$ \\
Cenizas & $0,40-0,50$ \\
\hline
\end{tabular}


Beneficio del cacao. Según MEJÍA \& ARGÜELLO (2000), el proceso de beneficio de cacao comprende las etapas de desgrane, fermentación y secado.

1) Desgrane: involucra la partida de las mazorcas empleando un machete o mazo en forma perpendicular a su mayor diámetro, para luego extraer los granos de la placenta en forma manual. El tiempo de desgrane (tiempo transcurrido entre la toma de mazorca del árbol y la extracción del grano) afecta el proceso de fermentación, razón por la cual éste debe variar entre uno y dos días, porque cuando se emplea un mayor tiempo origina el inicio de la fermentación dentro de la mazorca.

2) Fermentación: proceso que se lleva a cabo en fermentadores, dura entre 7 y 8 días en los cuales la masa de cacao se voltea con el fin de airearla y lograr una fermentación uniforme. El objeto de este proceso es desprender los granos de la pulpa mucilaginosa que los protege, provocar la muerte del embrión para impedir la germinación de los granos y desencadenar modificaciones bioquímicas en el interior de los cotiledones que se traducen en un aumento de volumen, aparición del color pardo, disminución del sabor amargo y de la astringencia, permitiendo de esta manera el desarrollo de los precursores del aroma.

Según AUGSTBURGER et al. (2000), el proceso de fermentación se desarrolla así:

1) 1er día: Pulpa muy ácida ( $\mathrm{pH} 3,5)$, masa fermentante de color blanco, $\mathrm{pH}$ 6,5 del interior de la semilla, interior de la semilla de color violeta, no hay desarrollo de calor, olor agridulce, aromático. 2) 3er-4º día: Masa fermentante está ácida (pH 4,5), de color café claro, $\mathrm{pH}$ 4,5 del interior de la semilla, de color violeta, sus bordes de color café, aumento de temperatura de la masa fermentante a $45-50^{\circ} \mathrm{C}$, fuerte olor a ácido acético. 3) $5^{\circ}-7^{\circ}$ día: Masa fermentante está acidulada (pH 5,5), masa fermentante de color café, pH 5,5 del interior de la semilla, de color café, temperatura de la masa fermentada se reduce a $40^{\circ} \mathrm{C}$, el olor a ácido acético es menos fuerte.

Por otro lado, ENRÍQUEZ (1985) indica que:

En las primeras horas de la fermentación la emisión de jugos azucarados de las almendras de cacao es bastante, puesto que proceden del inicio de la descomposición de la pulpa que rodea las semillas o hilio de la mazorca. Estima que la producción está alrededor de 4 a 6 litros por cada $100 \mathrm{~kg}$ de masa, y que durante las 6 horas siguientes, se obtiene un poco menos de la mitad (casi 3 L por cada $100 \mathrm{~kg}$ de masa) de jugos. Esta emisión cesa casi completamente cuando han transcurrido 24 horas.

3) Secado: su objetivo es disminuir el contenido de humedad, la acidez y la astringencia logrando el desarrollo del color chocolate característico de los granos bien fermentados.

Cualidades y características de los suelos con cultivos de cacao. Los suelos deben reunir ciertas características como: suelos preferiblemente profundos y bien drenados, pero a su vez con buenas condiciones de retención de humedad, buen contenido de materia orgánica y pH entre 5,5 y 7,5 (GARCÍA-LOZANO et al., 2006), tal como se aprecia en la Figura 2, en donde se exhiben las características y su requerimiento para el cultivo de cacao. 


\section{CARACTERÍSTICA}

\begin{tabular}{|c|c|}
\hline \multicolumn{2}{|c|}{\begin{tabular}{|l} 
Topografía \\
Rango de Altitud
\end{tabular}} \\
\hline Clima & $\begin{array}{l}\text { Temperatura variación } \\
\text { anual }\end{array}$ \\
\hline \multirow{5}{*}{ Suelo } & $\begin{array}{l}\text { Precipitación variación } \\
\text { anual } \\
\text { Distribución períodos } \\
\text { de lluvia }\end{array}$ \\
\hline & Humedad relativa \\
\hline & Vientos \\
\hline & PH \\
\hline & $\begin{array}{l}\text { Textura } \\
\text { Estructura }\end{array}$ \\
\hline
\end{tabular}

Nivel freático

Fertilidad
REQUERIDA PARA EL

CULTIVO

Plana a ondulada

o a 1.000 m.s.n.m

$23-30 \circ \mathrm{C}$ Promedio $25 \circ \mathrm{C}$

$1.500-2.500$ m.m.

Constante en el año-Bimodal.

75- $85 \%$

Baja tolerancia a vientos

4,5- 6.8

Franco Arcilloso - Arenoso

Granular

Mayor de 1 metro

De acuerdo al Análisis de

suelos.

Figura 2. Características de los suelos con cultivo de cacao. Según VALENZUELA (2012).

El suelo como soporte y fuente de nutrientes para las plantas. LÓPEZ (2002) reporta que el suelo es el soporte de las actividades del hombre dirigidas al aprovechamiento de su uso potencial productivo para la generación de biomasa. En este sentido, se hace necesario hablar de la calidad del suelo, para el alcance de la sostenibilidad de los sistemas de producción basados en el aprovechamiento del suelo en su función primaria: como despensa y soporte de las plantas (productor de biomasa). La calidad del suelo puede ser definida como la capacidad del suelo para funcionar de una manera para producir cultivos, animales y seres humanos saludables, resistir la degradación y para minimizar impactos ambientales, por tanto entra a ser el producto de componentes químicos, físicos y biológicos del suelo y sus interacciones.

Hoy en día la actividad agrícola genera gran cantidad de desechos, que en la mayoría de los casos van a parar al suelo y éste actúa como medio receptor. El aporte en cantidades superiores a las que puede asimilar produce efectos que se manifiestan en alteraciones de la capacidad de su uso primario, es decir como soporte y fuente de nutrientes para las plantas, para la producción de biomasa, afectando así la calidad del mismo (LÓPEZ, 2002).

Factor organismos en el suelo. LABRADOR (2008) destaca que el suelo, además de ser soporte y fuente de nutrientes de las plantas, es el hábitat de una gran variedad de organismos, es decir que la dinámica de la vida que se da en él asegura la multiplicidad de los servicios ecológicos. Por lo mencionado anteriormente, puede decirse que la cantidad como diversidad de organismos en el suelo varía, de acuerdo a las condiciones de uso y manejo del suelo, a algunas propiedades tanto físicas como químicas y a condiciones ambientales. 
Por consiguiente, los organismos del suelo se constituyen en el agente principal del ciclo de los nutrientes, regulan la retención del carbono y la emisión de gases efecto invernadero, la dinámica de la materia orgánica del suelo, modifican la estructura material del mismo y los regímenes del agua, de esta manera los organismos mejoran la eficacia para el suministro y asimilación de los nutrientes por parte de las plantas (LABRADOR, 2008). Es así como la biota del suelo la compone el conjunto de la fauna y la flora que vive en él; la gran mayoría de los organismos del suelo establecen una permanente competencia por nutrientes, oxígeno, humedad y espacio. Los organismos que integran la meso y macrobiota del suelo cumplen una función fundamental en la fragmentación, transformación y translocación de materiales orgánicos en él, aportando considerables cantidades de biomasa al suelo (CHAMORRO, 1989).

En este contexto, los restos de materia orgánica son fragmentados por la macrofauna, lo que facilita la biodegradación a cargo de bacterias y hongos del suelo, proporcionando con la mineralización de estos sustratos carbonados nutrientes inorgánicos fundamentales para el desarrollo vegetal (LABRADOR, 2008).

SILVA et al. (1992) reportan que el aporte de materia orgánica en el suelo se constituye en una fuente de alimentos y energía para los microorganismos y fauna, y sirve como fuente de N, P, y S a través de su mineralización por los microorganismos del suelo.

El magnesio, el potasio, el calcio y el fósforo en el suelo. Según BARBER (1995), el magnesio se encuentra en el suelo en tres fracciones como: 1) Catión intercambiable en el complejo de cambio: esta forma es la más importante, pues permite determinar el magnesio disponible. 2) Constituyente de minerales: en esta el magnesio es un componente de los minerales primarios del suelo; como el proceso de descomposición de minerales es muy lento, esta forma de magnesio no está disponible para las plantas. 3) En la solución del suelo: en esta forma se encuentra en equilibrio con el magnesio intercambiable, por lo tanto está disponible para las plantas. Lo citado, sin tener presente las pequeñas cantidades de magnesio que se hallan en las fracciones orgánicas.

BARBER (1995) expone que el potasio en el suelo generalmente se encuentra en cuatro formas: 1) Potasio estructural: se encuentra en el suelo en la estructura cristalina de los feldespatos, arcillas y micas. 2) Potasio intercambiable: es fracción disponible del potasio en el suelo, que las plantas pueden extraer fácilmente. 3) Potasio fijado: atrapado en el espacio interior de las arcillas. 4) Potasio en la solución del suelo: esta forma está inmediatamente disponible para las plantas. Sin embargo, las cantidades presentes en la solución del suelo son muy pequeñas.

Respecto al calcio, este elemento forma compuestos insolubles con otros elementos en el suelo, y la cantidad del mismo depende del material parental así como de la aplicación de enmiendas y del grado de meteorización (BARBER, 1995). Su concentración en el suelo generalmente supera las necesarias para un adecuado crecimiento de las plantas, aunque su absorción por parte de ellas es genéticamente controlada (HAVLIN et al., 1999).

Por otro lado, según LEÓN (2001), en el suelo el fósforo se halla en forma orgánica como inorgánica y su solubilidad en el mismo es baja. Los tipos de compuestos en 
función de este elemento son determinados por el pH del suelo y por la cantidad y el tipo de minerales presentes en el suelo. Este mismo autor plantea que en suelos ácidos este elemento tiene tendencia a reaccionar con el hierro, aluminio y el manganeso, y en suelos alcalinos su fijación es con el calcio, para lo cual establece que el rango óptimo en función del pH para su disponibilidad máxima es de 6,07,0 . Indica, igualmente, que la deficiencia de este elemento en las plantas ocasiona retrasos en el crecimiento. Adicionalmente, cita que la movilidad en el suelo del fósforo es muy limitada, de ahí a que las raíces lo absorban de su entorno inmediato, por lo que su concentración resulta ser mayor en ellas que en la misma solución del suelo. Este es un proceso en el que se consume energía, por eso condiciones como bajas temperaturas, exceso de agua, entre otras, inhiben la actividad de las raíces y, por ende, la absorción de fósforo.

\section{MATERIAL Y MÉTODOS}

El estudio se realizó en la Finca Bruselas 6 en el municipio de Yaguará, situado sobre los valles del río del mismo nombre y el Magdalena, en la parte centro del departamento del Huila, en la vertiente oriental de la Cordillera Central, comunicándose con la capital del departamento del Huila a una distancia de $49 \mathrm{~km}$. La extensión total del territorio del municipio es de $329 \mathrm{~km}^{2}$, equivalente al 1,6\% del área departamental (POT, 2012). La finca referenciada está ubicada en la vereda Bajo Vilú, sobre la cota 560 del embalse de Betania; cuenta con 1800 árboles de cacao y en menores cantidades frutales como palmas de coco, palmas de cachipay, árboles de guanábano y de mango, entre otros. La finca presenta una superficie de 1,3 ha; los tipos de cacao que se registraron corresponden a criollos, forasteros e híbridos, para dicha clasificación se recurrió a los criterios diferenciales entre los grupos de cacao a nivel morfológico de acuerdo con GARCÍA-CARRIÓN (2008) en su trabajo sobre Estudio de caracterización del potencial genético del cacao en Perú. La edad de la plantación es de 12 años, tiempo en el que se ha recurrido al empleo de fertilizantes como triple 15, ceniza y gallinaza. Dicho cultivo no ha recibido asistencia técnica ni financiamiento o ayudas. Respecto a la producción reporta 600 $\mathrm{kg} / \mathrm{ha}$. Las enfermedades que se evidenciaron fueron moniliasis, mal de machete y mazorca negra, para su determinación se recurrió a los módulos técnicos de cacao de FEDECACAO/PRONATTA (2004), en lo referente a enfermedades donde se detallan los síntomas o diagnóstico de las mismas. En la finca de estudio se delimitó un área $50 \mathrm{~m}^{2}$ con dimensiones $5 \times 10 \mathrm{~m}$. Se hizo uso de la asignación aleatoria simple para la toma de las muestras y de la prueba de hipótesis mediante el programa estadístico MegaStat, con 3 repeticiones, con un nivel de confianza del 95\%.

Los tratamientos fueron: 1) Suelo con vertimiento de exudado y cáscara de cacao (T1), y 2) Suelo sin vertimiento de los subproductos del beneficio del cacao (patrón).

Las respectivas muestras corresponden a los siguientes tiempos desde el inicio del primer vertimiento: 1) T1-1: 5 meses, 2) T1-2: 13 meses, y 3) T1-3: 15 meses.

En este trabajo, la variable experimental (suelo) se expuso a la variable independiente (exudado y cáscara del T. cacao) y posteriormente se comparó con la muestra control (sin depósito de subproductos), empleándose el nivel mínimo de manipulación de dos grados: presencia-ausencia (HERNÁNDEZ-SAMPIERI et al., 2006), con el fin de determinar si el suelo expuesto a la variable independiente difiere del suelo que no 
fue expuesto. Inicialmente se realizó un análisis de algunas propiedades químicas y biológicas del suelo en un área de $50 \mathrm{~m}^{2}$ para tener como patrón de referencia del efecto del vertimiento. El tipo de muestreo fue al azar en zig-zag, tomándose 15 submuestras a lo largo y ancho del área a una profundidad aproximada de $20 \mathrm{~cm}$ y mezclando posteriormente en un balde para homogenizar de acuerdo a lo establecido por el IGAC (2013), para el muestreo de suelos. Para los datos de las cáscaras, se clasificaron en función del grosor de las mismas y, a su vez, en grandes, medianas y pequeñas teniendo en cuenta su longitud. De cada una de esta subclasificación se tomaron cinco mazorcas, a las cuales se les registró su debido peso. Aquellas que presentaron cáscara gruesa [Tabla 4, Ecuación (1)] y aquellas de cáscara delgada [Tabla 5, Ecuación (2)], estableciéndose un peso promedio para el peso de las cáscaras [Ecuación (3)], el cual se empleó para determinar el peso de la cantidad de cáscaras depositadas. Asimismo, con el exudado se tomó como referencia lo citado por MEJÍA \& ARGÜELLO (2000): "se pueden obtener aproximadamente 40 litros de pulpa provenientes de 800 kilogramos de semilla húmeda". Es decir, que por cada $\mathrm{kg}$ de semilla fresca se producen $0,05 \mathrm{~L}$ de exudado, factor que se empleó para determinar el volumen de vertimiento de exudado (Tabla 6). En el área dispuesta se llevó a cabo el vertimiento de los dos subproductos del beneficio de cacao las cáscaras y el exudado, con una frecuencia de vertimiento de 8 a 15 días por un lapso de 5 meses (Tabla 6), igualmente se tuvo en cuenta las precipitaciones registradas durante el trabajo (Figura 3).

Los métodos empleados para conocer el valor de algunas propiedades químicas y biológicas del suelo se citan a continuación, de acuerdo a lo efectuado por el Laboratorio Nacional de Suelos del Instituto Geográfico Agustín Codazzi, el Laboratorio de Recursos Agroambientales de la Universidad Surcolombiana y, posteriormente, asumidas por el investigador.

Para las propiedades físicas y químicas: $\mathrm{pH}$ : método potenciométrico. Magnesio, potasio y calcio: método $\mathrm{NH}_{4} \mathrm{OAc}$ - AA. Fósforo: por el método Bray II. Relación $\mathrm{Ca} / \mathrm{Mg}$, Relación $(\mathrm{Ca}+\mathrm{Mg}) / \mathrm{K}$ : por relaciones catiónicas.

Los resultados se presentan en la Tabla 7. Los resultados estadísticos de la hipótesis en la Tabla 8. En la Tabla 9 las relaciones catiónicas. Y las variaciones registradas para los parámetros de $\mathrm{pH}$, magnesio, potasio, calcio y fósforo en las figuras 4,5 , $6,7,8$, respectivamente.

Para las propiedades biológicas: La cuantificación de microorganismos fijadores de nitrógeno, bacterias, hongos y solubilizadores de fosfato: método de conteo en placa por siembra en superficie. Los resultados se presentan en la Tabla 10, los resultados estadísticos de la hipótesis en la Tabla 11, y las variaciones registradas para los parámetros de hongos, bacterias, fijadores de nitrógeno y solubilizadores de fosfato en las figuras 9,10, 11, 12, respectivamente. 


\section{RESULTADOS Y DISCUSIÓN}

Las mazorcas de cacao dispuestas para este trabajo correspondieron a los tipos hallados en Finca Bruselas 6 del municipio de Yaguará en el departamento del Huila, como fueron híbridos, forasteros y criollos de acuerdo a los parámetros citados por GARCÍA-CARRIÓN (2008) sobre caracteres diferenciales de los grupos de cacao: criollo, forastero y trinitario.

Las tablas 4 y 5 reportan información del peso de las cáscaras en función de su grosor, y en la Tabla 6 se presenta la frecuencia del vertimiento y la cantidad de subproductos del beneficio de cacao depositados al suelo.

Tabla 4. Peso de las cáscaras gruesas de cacao.

\begin{tabular}{ccc}
\hline Tamańo de las mazorca & Longitud $(\mathbf{c m})$ & Peso $(\mathbf{k g})$ \\
\hline Grande & $\geq 20$ & 1,1 \\
Mediano & 15 a 19 & 0,65 \\
Pequeńa & 10 a 14 & 0,375 \\
\hline
\end{tabular}

$\overline{\mathbf{X}}_{=} \frac{1,1+0,65+0,375}{3}=0,7 \mathrm{~kg}$ promedio cáscara gruesa

Tabla 5. Peso de las cáscaras delgadas de cacao.

\begin{tabular}{ccc}
\hline Tamańo de las mazorca & Longitud $(\mathbf{c m})$ & Peso $(\mathbf{k g})$ \\
\hline Grande & $\geq 20$ & 0,6 \\
Mediano & 15 a 19 & 0,375 \\
Pequeña & 10 a 14 & 0,250 \\
\hline
\end{tabular}

$\overline{\mathbf{X}}=\frac{0,6+0,375+0,250}{3}=0,4 \mathrm{~kg}$ promedio cáscara delgada

Promedio peso de la cáscara de cacao a tener en cuenta:

$\overline{\mathbf{X}}=\underline{0,7+0,4}=0,55 \mathrm{~kg}$ 
Tabla 6. Frecuencia de vertimiento de los subproductos del beneficio del cacao.

\begin{tabular}{|c|c|c|c|c|c|}
\hline \multirow{2}{*}{ Mes } & \multirow{2}{*}{ Frecuencia } & \multirow{2}{*}{$\begin{array}{l}\text { Cantidad de maz- } \\
\text { orcas recolectadas }\end{array}$} & \multirow{2}{*}{$\begin{array}{l}\text { Masa fresca de } \\
\text { cacao }(\mathbf{k g})\end{array}$} & \multicolumn{2}{|c|}{$\begin{array}{l}\text { Cantidad de vertimiento de los } \\
\text { subproductos del beneficio }\end{array}$} \\
\hline & & & & Cáscaras (kg) & Exudado (L) \\
\hline \multirow{4}{*}{1} & 1 & 389 & 85,5 & 213,95 & 4,275 \\
\hline & 2 & 394 & 86,6 & 216,7 & 4,33 \\
\hline & 3 & 391 & 86 & 215,05 & 4,3 \\
\hline & 4 & 397 & 87,3 & 218,35 & 4,365 \\
\hline \multirow{4}{*}{2} & 1 & 394 & 86,7 & 216,7 & 4,335 \\
\hline & 2 & 405 & 89 & 222,75 & 4,45 \\
\hline & 3 & 402 & 88,5 & 221,1 & 4,425 \\
\hline & 4 & 398 & 87,5 & 218,9 & 4,375 \\
\hline \multirow{2}{*}{3} & 1 & 390 & 85,8 & 214,5 & 4,29 \\
\hline & 2 & 378 & 83,2 & 207,9 & 4,16 \\
\hline \multirow{2}{*}{4} & 1 & 376 & 83 & 206,8 & 4,15 \\
\hline & 2 & 373 & 82 & 205,15 & 4,1 \\
\hline \multirow{2}{*}{5} & 1 & 391 & 86 & 215,05 & 4,3 \\
\hline & 2 & 386 & 85 & 212,3 & 4,25 \\
\hline \multicolumn{2}{|c|}{ Total } & 5464 & 1202,1 & 3005,2 & 60,105 \\
\hline
\end{tabular}

Los datos registrados en la Tabla 6, indican que en el suelo destinado para determinar el efecto de los subproductos del beneficio de cacao se vertieron aproximadamente tres toneladas de cáscara de cacao (peso fresco) y 60 litros de exudado.

Otros datos considerados son los referentes a las precipitaciones presentadas en el municipio de Yaguará (Huila), durante el tiempo de trabajo (Figura 3), puesto que este factor influye en el proceso de descomposición del material orgánico.

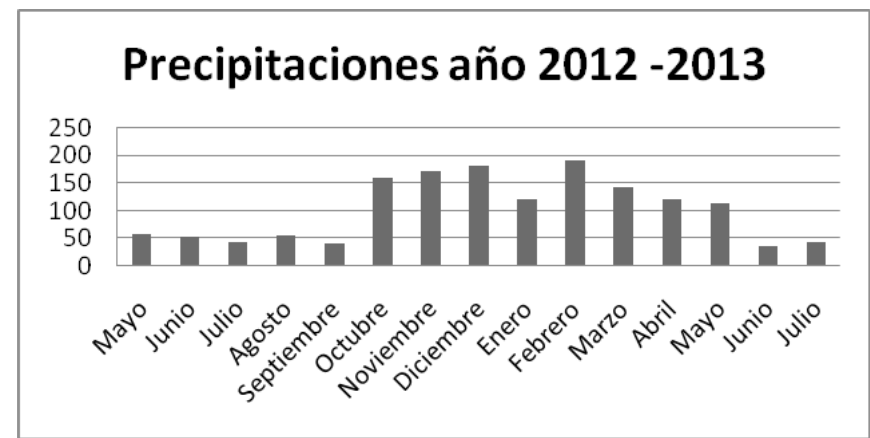

Figura 3. Registro de precipitaciones periodo de estudio año 2012-2013, municipio de Yaguará (Huila). Según la Estación Metereológica de Yaguará. 
Caracterización química. En la Tabla 7 se presenta la información correspondiente a los resultados de las propiedades químicas del suelo objeto de estudio.

Tabla 7. Parámetros químicos analizados.

\begin{tabular}{|c|c|c|c|c|c|}
\hline \multirow{2}{*}{$\begin{array}{l}\text { Parámetros } \\
\text { químicos }\end{array}$} & \multirow{2}{*}{ Unidad } & \multirow{2}{*}{ Patrón } & \multicolumn{3}{|c|}{ Tratamiento $\mathrm{T} 1$} \\
\hline & & & T1-1 & T1-2 & T1-3 \\
\hline $\mathrm{pH}$ & - & 8,09 & 6,55 & 6,30 & 6,2 \\
\hline Magnesio $(\mathrm{Mg})$ & $\mathrm{Cmol}+. \mathrm{kg}^{-1}$ & 4,81 & 2,27 & 2,13 & 2,11 \\
\hline Potasio $(\mathrm{K})$ & $\mathrm{Cmol}+\mathrm{kg}^{-1}$ & 1,64 & 0,06 & 0,06 & 0,04 \\
\hline Calcio (Ca) & $\mathrm{Cmol}+. \mathrm{kg}^{-1}$ & 9,47 & 8,81 & 8,75 & 8,76 \\
\hline Fósforo (P) & ppm & 100,2 & 37,1 & 45,6 & 45,8 \\
\hline
\end{tabular}

Se presentó una notable variación de las propiedades evaluadas, $\mathrm{pH}$, magnesio, potasio, calcio, fósforo y la relación entre cationes, comportamiento que en este trabajo obedece al proceso de descomposición de los materiales orgánicos depositados en el suelo, rechazando la hipótesis nula para cada uno de los parámetros evaluados, lo cual comprueba el efecto de éstos en el suelo (Tabla 8).

ZAPATA (2004) señala que este evento de descomposición implica la oxidación de los restos orgánicos, en donde inicialmente estos materiales sufren un fraccionamiento que facilita el ataque microbial dándose la descomposición siempre y cuando existan condiciones óptimas como humedad, aireación y temperatura. Asimismo, plantea que la adición de materia orgánica en el suelo puede provocar un incremento o una disminución del $\mathrm{pH}$, dependiendo de la influencia en el balance de protones. Que en suelos alcalinos se presenta una disminución del pH cuando se adiciona material orgánico, siendo éste el efecto ocurrido con el vertimiento de los subproductos del beneficio del cacao (Tabla 7), esto debido -como lo cita el autor en mención- a la mineralización del nitrógeno, del azufre y del fósforo orgánico, a la disociación de ligados orgánicos e hidratación del dióxido de carbono generado en la descomposición de estos materiales.

Esta situación, igualmente, se debe a la mismas características químicas de los subproductos vertidos, puesto que los porcentajes de humedad son altos para las cáscaras (85\%) y para el exudado entre 79,2 y 84,2\% según MEJÍA \& ARGÜELLO (2000), lo que facilita aún más su descomposición por parte de los microorganismos y, por ende, un aumento poblacional como se evidenció en los parámetros biológicos, lo que lleva a una mayor liberación de exudados por parte de ellos que contribuyen a la acidificación del suelo, asimismo otro factor involucrado son los procesos respiratorios que realizan, como también los metabólicos que generan dióxido de carbono y ácidos orgánicos solubles que se comportan como ácidos libres en el suelo (ZAPATA, 2004). 
En cuanto al magnesio, al potasio y al calcio, SÁENZ (1991) indica que la deficiencia de ellos incide, respectivamente, en los contenidos de grasa en las semillas, el fortalecimiento de los tejidos, la formación de la cáscara del fruto y la caída prematura de las hojas y muerte de los brotes. En este estudio fue evidente la notable disminución en estos elementos, la razón obedece posiblemente a la misma acidificación del suelo en la cual hay pérdida por lavado de cationes no ácidos como estos (ZAPATA, 2004), asimismo se refiere (LEÓN, 2001) que las deficiencias de magnesio tienden a ocurrir cuando los suelos son ácidos.

BARBER (1995) explica que en suelos de bajo pH la solubilidad del magnesio tiende a disminuir, indicando igualmente que en esta condición del suelo aumenta la tendencia de lixiviación del mismo, la razón expuesta es que tienen menos sitios intercambiables.

El potasio, según BARBER (1995), indica que el pH del suelo al bajar reduce la tendencia a la fijación de potasio debido -según el autor- a la presencia de polímeros de hidróxido de aluminio que ocasionan este efecto, caso que posiblemente ocurrió en este trabajo.

En la Figura 8 se aprecia que el fósforo presentó una reducción drástica, la muestra patrón registró 100,2 ppm y posteriormente arrojó un registro de 37,1ppm, este comportamiento inicial pudo obedecer a la inmovilización, la cual se presenta cuando las formas disponibles de fósforo son consumidas por microorganismos, es decir, que el fósforo se convierte en fósforo orgánico con representación en la biomasa, el cual no es disponible (FERNÁNDEZ et al., 2005) y lo que se registró en los resultados fue en función del fósforo disponible en el suelo. Asimismo, este descenso también pudo haber ocurrido por la reacción del fósforo soluble que había inicialmente con iones como el calcio, el aluminio o el hierro, lo cual produce su precipitación, disminuyendo por ende su disponibilidad (FERNÁNDEZ et al., 2005). Posteriormente se observó un aumento y se encontró una relación proporcional, posiblemente debido al grupo de organismos solubilizadores, los cuales hacen que se solubilice el fósforo a partir de la producción de ácidos orgánicos haciendo solubles las formas insolubles de fosfatos y mejorando así su disponibilidad (VERA et al., 2002).

El orden que siguieron los cationes intercambiables de acuerdo con los resultados fue $\mathrm{Ca}>\mathrm{Mg}>\mathrm{K}$, este orden -según SADEGHIAN-KHALAJABADI (2012)- sigue la serie liotrópica, la cual determina la preferencia general de los suelos. Al revisar las relaciones $\mathrm{Ca} / \mathrm{Mg}$, $(\mathrm{Ca}+\mathrm{Mg}) / \mathrm{K}$, con los datos registrados en la Tabla 7 de cada uno de los cationes se evidenció aumento en ellas (Tabla 8), este comportamiento tiene su origen probablemente por la disminución de los valores de magnesio y potasio producto, quizás, del descenso del $\mathrm{pH}$ por el vertimiento de los subproductos del beneficio del cacao como se explicó anteriormente.

Tabla 8. Relaciones catiónicas

\begin{tabular}{lllll}
\hline \multirow{2}{*}{ Relaciones catiónicas } & \multirow{2}{*}{ Patrón } & \multicolumn{3}{c}{ Tratamiento T1 } \\
\cline { 3 - 5 } & & T1-1 & T1-2 & T1-3 \\
\hline Relación $\mathrm{Ca} / \mathrm{Mg}$ & 1,97 & 3,88 &, 10 & 4,15 \\
Relación $(\mathrm{Ca}+\mathrm{Mg}) / \mathrm{K}$ & 8,71 & 184,67 & 181,3 & 271,75 \\
\hline
\end{tabular}


Al relacionar los resultados obtenidos en estos parámetros con los requerimientos ecofisiológico y de manejo para el cultivo de cacao en Colombia emitidos por SIGCORPOICA (2004), se encontró que en el factor de diagnóstico del pH la disminución hallada ubica a este suelo como sumamente apto para el cultivo, puesto que está en el rango de 5,5, a 6,5. Para el factor magnesio está por encima del rango 1 a 1,5 Cmol+. $\mathrm{kg}^{-1}$, para lo cual NAVARRO \& NAVARRO (2003) manifiestan que ante un contenido elevado de magnesio los suelos sufren de deficiencia de potasio, situación que se evidenció en este trabajo, pese a que el nivel de magnesio bajó, sin embargo entra a ser un valor alto para la referencia antes citada; y el de potasio, que en la misma referencia lo cataloga como no apto para el cultivo de cacao, pasó de un valor de 1,64 a 0,04 Cmol+.kg-1 (Figura 6). Asimismo, estos autores afirman que este panorama hace que las plantas no puedan usar con éxito el poco potasio que existe en el suelo, ocasionando disminución en su vigor, por lo cual su crecimiento se verá retardado.

VERA et al. (2000) exponen que las características químicas de los suelos entran a ser una de las principales limitantes para el desarrollo y producción del cacao. Entre las que se cuentan los bajos niveles de $\mathrm{pH}$, fósforo, calcio, magnesio, potasio en el suelo, lo que se constituye en un indicativo para aplicar fertilizantes y enmiendas con el objeto de mejorar el contenido y balance de nutrientes en el suelo y, por ende, su funcionamiento global.

Tabla 9. Aplicación de prueba de hipótesis - parámetros químicos.

\begin{tabular}{|c|c|c|c|c|c|}
\hline Parámetros químicos & $\begin{array}{l}\text { Valor hipótesis } \\
\mathbf{H}_{0}\end{array}$ & Datos & $\begin{array}{l}\text { Desviación } \\
\text { estándar }\end{array}$ & $\begin{array}{l}\text { Error } \\
\text { estándar }\end{array}$ & $\begin{array}{l}\text { p-Valor } \\
\text { (dos colas) }\end{array}$ \\
\hline $\mathrm{pH}$ & 8,0000 & 6,3500 & 0,1803 & 0,1041 & \multirow{5}{*}{$\begin{array}{l}0,0040 \text { e rechaza } \mathrm{H}_{0} \\
0,0008 \\
\text { se rechaza } \mathrm{H}_{0} \\
4,96 \mathrm{E}-05 \\
\text { se rechaza } \mathrm{H}_{0} \\
0,0066 \\
\text { se rechaza } \mathrm{H}_{0} \\
0,0025 \\
\text { se rechaza } \mathrm{H}\end{array}$} \\
\hline Magnesio (Mg) & 4,00000 & 2,17000 & 0,08718 & 0,05033 & \\
\hline Potasio $(\mathrm{K})$ & 1,00000 & 0,05333 & 0,01155 & 0,00667 & \\
\hline Calcio $(\mathrm{Ca})$ & 9,00000 & 8,77333 & 0,03215 & 0,01856 & \\
\hline Fósforo (P) & 100,0000 & 42,8333 & 4,9662 & 2,8672 & \\
\hline
\end{tabular}

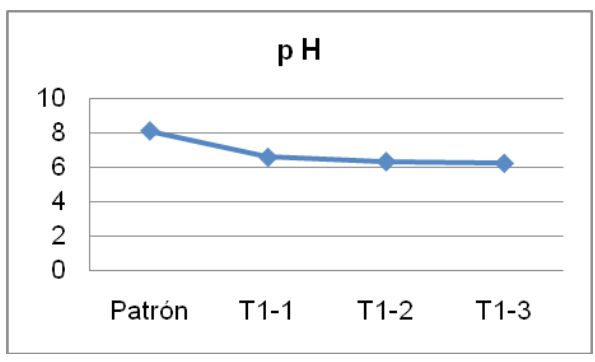

Figura 4. $\mathrm{pH}$ analizado

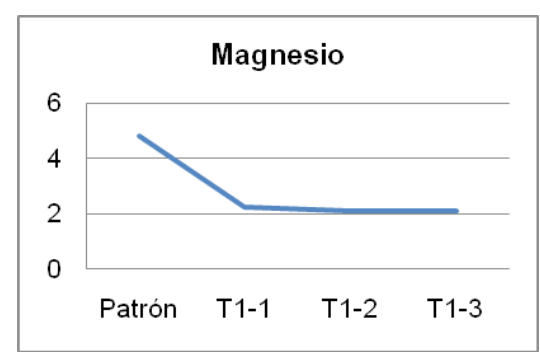

Figura 5. Magnesio analizado. 


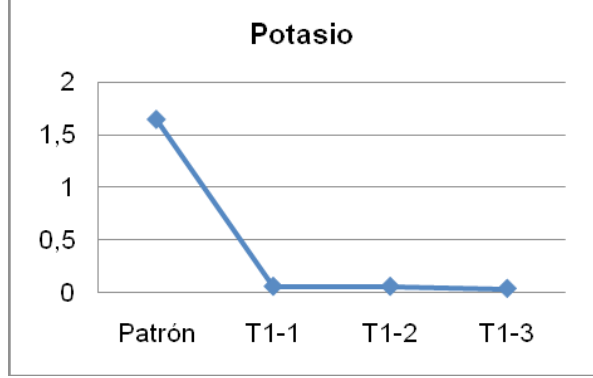

Figura 6. Potasio analizado.

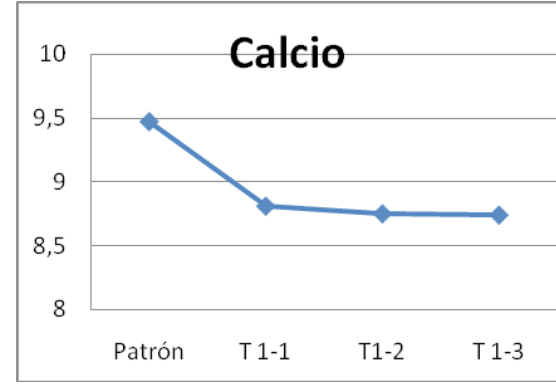

Figura 7. Potasio analizado

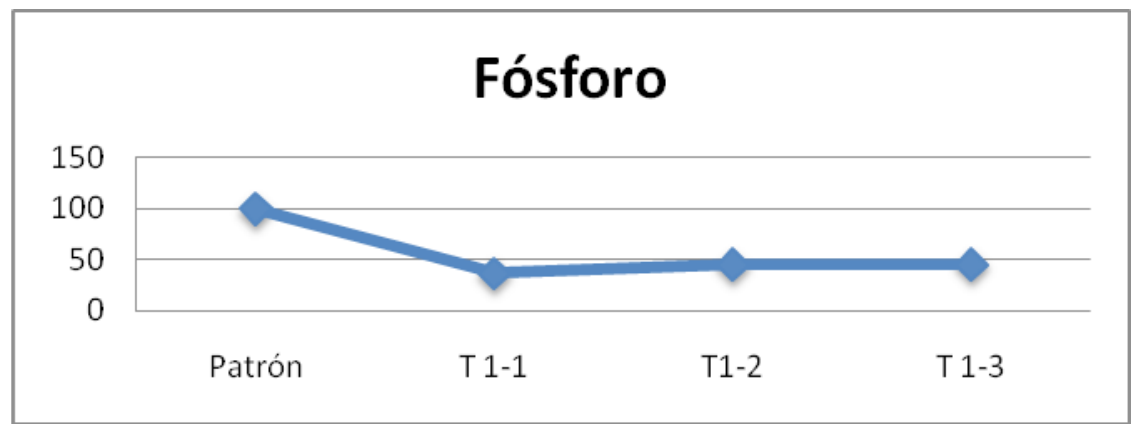

Figura 8. Fósforo analizado.

Caracterización biológica. Al evaluar el efecto del vertimiento de los subproductos del beneficio del cacao sobre los tres parámetros biológicos se evidencia el efecto ocurrido, comprobando la hipótesis formulada para cada uno de ellos.

Respecto al parámetro de los hongos y las bacterias heterótrofas, se evidenció que este grupo de microorganismos en T1-1 presentó un descenso poblacional que pudo haber sido producto de la escasa precipitación que se registró en la época seca, septiembre de 2012 (Figura 3). A medida que transcurrió el tiempo su población aumentó, tal como lo registraron los análisis posteriores (Tabla 10). Esto obedece a lo que expresa REY-PAZOS (2007), que la progresión del desarrollo de colonias puede ser producto del descenso del pH del suelo, el cual se registró, y de la etapa final de la degradación del material orgánico en el mismo. Situación que favorece su densidad y la actividad microbiana de estos grupos, dadas las condiciones óptimas para su fomento como lo destacan KOLMANS \& VÁSQUEZ (1996), ayudando así a mejorar la fertilidad del suelo al considerar la calidad y cantidad de los nutrientes producto de su metabolismo, factor que no se evaluó en este estudio.

De estos dos grupos estudiados, el que presentó mayor abundancia en el suelo fue el de las bacterias, quizás por ser capaces de crecer más rápidamente como lo afirma CAMPOS (2008), debido a la composición química de los subproductos depositados en el suelo (tablas 1 y 3) los cuales emplean como fuente de carbono y de nitrógeno (figuras 9 y 10). 
Por otro lado, el parámetro de los fijadores de nitrógeno presentó aumento en sus colonias en los registros efectuados, esto debido -como lo cita BOLAÑOSBENAVIDES (1998)- a las condiciones favorables del tipo de material orgánico dispuesto en el suelo, de la cantidad que se esté descomponiendo, por la heterogeneidad de este grupo de microorganismos, o también probablemente a que estos organismos presentan ventaja metabólica sobre los otros y, por lo tanto, tienden a aumentar sus poblaciones.

El comportamiento presentado por los solubilizadores de fosfatos (Figura 12) muestra un aumento poblacional con respecto a la muestra patrón, este resultado se relaciona posiblemente con las condiciones favorables para su crecimiento y desarrollo en este tipo de hábitat, entre ellas el contenido y la composición de la materia orgánica que provoca un aumento de la disponiblidad de sustratos metabolizables, lo que lleva a un incremento de microorganismos descomponedores entre los que se destacan los de capacidad solubilizadora (LUNA et al., 2002).

De hecho, el estudio de los parámetros biológicos resulta ser algo complejo debido a que no existen criterios definidos para establecer que todos los suelos presentan una densidad de hongos, bacterias, fijadores de nitrógeno y solubilizadores de fosfatos establecida, ya que hay que tener en cuenta la alta variabilidad del suelo dependiendo del orden del mismo, de las condiciones ambientales en que se ha dado ese orden, de los aspectos de manejo y de las variaciones de las partículas que lo integran. En este orden de ideas, en función de los fijadores de nitrógeno y de acuerdo a los criterios del Área de Biología del IGAC, (2013) cuando la población es $>1 \mathrm{E}+06$ es un indicativo de un suelo sometido a monocultivo y prácticas inapropiadas, dato que confirma el uso del área de estudio puesto que la población registrada estuvo por el orden de 8,9E+08 en la muestra patrón (Figura $11)$.

Tabla 10. Parámetros biológicos analizados.

\begin{tabular}{|c|c|c|c|c|c|}
\hline \multirow{2}{*}{ Parámetros biológicos } & \multirow{2}{*}{ Unidad } & \multirow{2}{*}{ Patrón } & \multicolumn{3}{|c|}{ Tratamiento } \\
\hline & & & T1-1 & T1-2 & T1-3 \\
\hline Hongos & $\begin{array}{l}\mathrm{UFC}^{*} / \mathrm{g} \text { o } \mathrm{ml} \mathrm{de} \\
\text { muestra }\end{array}$ & $2,2 \mathrm{E}+04$ & $7,7 \mathrm{E}+03$ & $8,90 \mathrm{E}+03$ & $9,20 \mathrm{E}+03$ \\
\hline Bacterias heterótrofas & $\begin{array}{l}\mathrm{UFC}^{*} / \mathrm{g} \text { o } \mathrm{ml} \mathrm{de} \\
\text { muestra }\end{array}$ & $2,0 \mathrm{E}+08$ & $1,2 \mathrm{E}+08$ & $1,30 \mathrm{E}+08$ & $1,4 \mathrm{E}+08$ \\
\hline Fijadores de nitrógeno & $\begin{array}{l}\mathrm{UFC}^{*} / \mathrm{g} \text { o } \mathrm{ml} \mathrm{de} \\
\text { muestra }\end{array}$ & $8,9 \mathrm{E}+07$ & $1,8 \mathrm{E}+08$ & $1,7 \mathrm{E}+08$ & $1,7 \mathrm{E}+08$ \\
\hline $\begin{array}{l}\text { Solubilizadores de fos- } \\
\text { fato }\end{array}$ & $\begin{array}{l}\mathrm{UFC}^{*} / \mathrm{g} \text { o ml de } \\
\text { muestra }\end{array}$ & $4,2 \mathrm{E}+06$ & $1,2 \mathrm{E}+07$ & $1,1 \mathrm{E}+07$ & $1,0 \mathrm{E}+07$ \\
\hline
\end{tabular}


Tabla 11. Aplicación de prueba de hipótesis - parámetros biológicos.

\begin{tabular}{llllll}
\hline $\begin{array}{l}\text { Parámetros } \\
\text { biológicos }\end{array}$ & $\begin{array}{l}\text { Valor } \\
\text { hipótesisH }\end{array}$ & Datos & $\begin{array}{l}\text { Desviación } \\
\text { estándar }\end{array}$ & $\begin{array}{l}\text { Error } \\
\text { estándar }\end{array}$ & $\begin{array}{l}\text { p-Valor } \\
\text { (dos colas) }\end{array}$ \\
\hline Hongos & $22.000,0000$ & $8.600,00000$ & 793,72539 & 458,25757 & $\begin{array}{l}0,0012 \\
\text { se rechaza } \\
\mathrm{H}_{0}\end{array}$ \\
$\begin{array}{l}\text { Bacterias } \\
\text { heterótrofas }\end{array}$ & $200.000 .000,0$ & $130.000 .000,0$ & $10.000 .000,0$ & $5.773 .502,6$ & $\begin{array}{l}0,006 \\
\text { se rechaza } \\
\mathrm{H}_{0}\end{array}$ \\
$\begin{array}{l}\text { Fijadores de } \\
\text { nitrógeno }\end{array}$ & $8.900 .000,0$ & $173.333 .333,3$ & $5.773 .502,6$ & $3.333 .333,3$ & $\begin{array}{l}0,0016 \\
\text { se rechaza } \\
\mathrm{H}_{0} \\
0,0071\end{array}$ \\
$\begin{array}{l}\text { Solubilizadores } \\
\text { de fosfato }\end{array}$ & $4.200 .000,0$ & $11.000 .000,0$ & $1.000 .000,0$ & $577.350,26$ & $\begin{array}{l}\text { se rechaza } \\
\mathrm{H}_{0}\end{array}$ \\
\hline
\end{tabular}

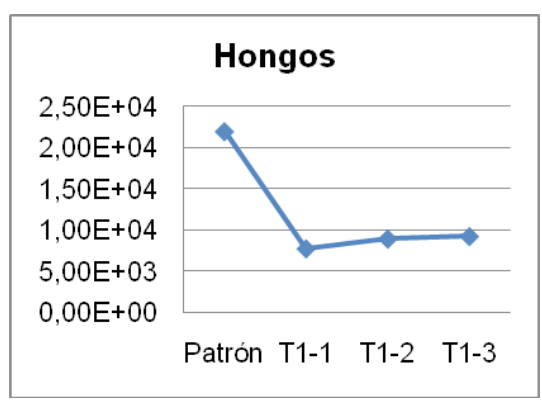

Figura 9. Población de hongos.

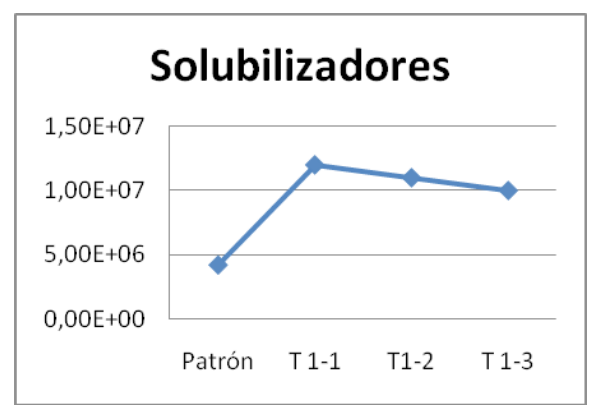

Figura 11. Fijadores de nitrógeno.

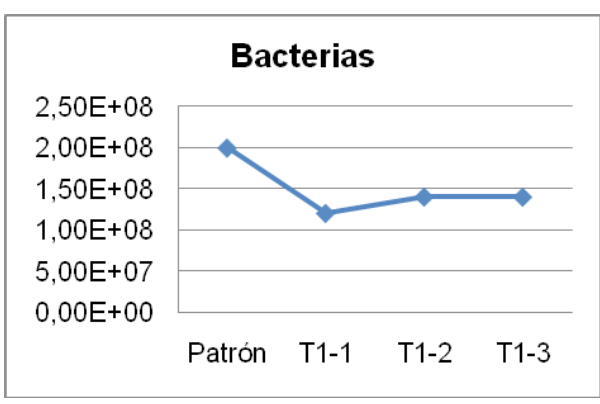

Figura 10. Población bacterias heterótrofas.

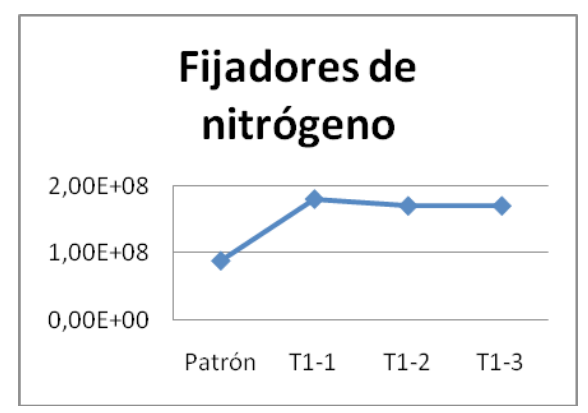

Figura 12. Solubilizadores de fosfatos. 


\section{CONCLUSIONES}

El efecto del vertimiento de subproductos en el suelo resultó variable por cada parámetro evaluado, de acuerdo con la prueba de hipótesis aplicada. No se encontró una relación directa concluyente que permitiera saber si son las cáscaras o el exudado lo que provoca la mayor variación, porque se asumieron en conjunto. En lugar de ello, se pudo determinar que la variabilidad de los parámetros considerados en el suelo está afectada por el tipo de subproductos, por ello se proponen algunas estrategias para su manejo como lo es el empleo de las cáscaras para alimentación de animales, elaboración de pectinas o como abono siempre y cuando se les dé el tratamiento adecuado en las composteras, asimismo el exudado resulta ser una alternativa atractiva para la elaboración de bebidas sean estas fermentadas o no, de néctares o como caso de estudios posteriores como agente modificador de $\mathrm{pH}$ para suelos alcalinos.

Los cambios en la composición química del suelo, luego del vertimiento de subproductos del beneficio del cacao, lleva a considerar que se presenta déficit de potasio, lo cual bien pudo haber sido por el nivel elevado de magnesio, pese a que éste también disminuyó con respecto a la muestra patrón posiblemente debido al descenso en el pH del suelo. Sin embargo, respecto a los parámetros biológicos, se presentó aumento poblacional de los grupos de microorganismos considerados en este estudio, lo anterior da a entender que es un reflejo de la fuente de alimentación y de las variaciones dadas en el suelo por ese mismo factor.

Las características químicas de los subproductos vertidos presentan porcentajes de humedad altos para las cáscaras (85\%) y para el exudado entre 79,2 y 84,2\%, esta condición facilitó aún más la descomposición por parte de los microorganismos y, por ende, el aumento poblacional, lo que llevó a una mayor liberación de exudados por parte de ellos contribuyendo de esta manera a la acidificación del suelo.

\section{BIBLIOGRAFÍA}

AUGSTBURGER, F., BERGER, J. \& CENSKOWSKY, U., 2000.- Agricultura orgánica en el trópico y subtrópico. Guía de Cacao. Asociación Naturland, Alemania.

BARBER, S.A., 1995.- Soil nutrient bioavailability; a mechanistic approach. John Wiley \& Sons, New York (USA).

BOLAÑOS-BENAVIDES, M.M., 1998.- El papel del componente biorgánico en la fertilidad de los suelos. CORPOICA, Armenia (Colombia).

CAMPOS, T., 2008.- Determinación de microorganismos benéficos de suelo. Biblioteca agropecuaria de Colombia. Bogotá (Colombia), 32 p.

CHAMORRO, C. 1989.- Efecto del uso del suelo sobre la composición edafofaunística de los páramos que circundan la ciudad de Bogotá. Suelos Ecuatoriales, 19 (1): 48-62.

ENRÍQUEZ, G.A., 1985.- Curso sobre el cultivo del cacao. Centro Interamericano de documentación e información Agrícola, Turrialba (Costa Rica).

ESPINAL, C.F., MARTÍNEZ H. \& ORTIZ, L., 2005.- La cadena del cacao en Colombia: una mirada global de su estructura y dinámica 1991-2005. Ministerio de Agricultura y Desarrollo Rural - Observatorio Agrocadenas Colombia, Bogotá (Colombia).

FEDECACAO/PRONATTA, 2004.- Módulos técnicos del cacao. Federación Nacional de Cacaoteros y Corporación Nacional de Transferencia de Tecnología, Bogotá (Colombia).

FERNÁNDEZ, Z.P., ZALBA, P., GÓMEZ, M.A. \& SAGARDOY, M.A., 2005.- Bacterias solubilizadoras de fosfato inorgánico aisladas de suelos de la región sojera. Revista Ciencia del Suelo (Argentina), 23 (1): 31 - 37.

GARCÍA-CARRIÓN, L.F., 2008.- Estudio de caracterización del potencial genético del cacao en Perú. M \& O Consulting S.A.C., Lima (Perú).

GARCÍA-LOZANO, J., ROMERO-CARRASCAL, M. \& ORTIZ, L.A., 2006.-Evaluación edafoclimática de las tierras del trópico bajo colombiano para el cultivo de cacao. CORPOICA, Cundinamarca (Colombia). 
HAVLIN, J.L., BEATON, J.D., TISDALE, S.L. \& NELSON, W.L., 1999.- Soil fertility and fertilizers; an introduction to nutrient management. Upper Saddle River, USA.

HERNÁNDEZ-SAMPIERI, R., BAPTISTA-LUCIO, P. \& FERNÁNDEZ-COLLADO, C., 2006.- Metodología de la investigación. $4^{\mathrm{a}}$ Edición. Editorial McGraw-Hill, México D.F. (México).

IGAC., 2013.- Criterios de aceptación de resultados para el área de biología. Instituto Geográfico "Agustín Codazzi". Disponible en http://www.igac.gov.co/igac

KOLMANS, E. \& VÁSQUEZ, D., 1996.- Estiércol y compost. Manual de Agroecología Ecológica, 3: 101-105.

LABRADOR, J., 2008.- Manejo del suelo en los sistemas agrícolas de producción ecológica. Sociedad Española de Agricultura Ecológica, Valencia (España).

LEÓN, L.A., 2001.- Las propiedades químicas de los suelos y su efecto sobre la disponibilidad de los nutrientes para las plantas (en) Manejo productivo de suelos para cultivos de alto rendimiento. Sociedad Colombiana de la Ciencia del Suelo, Comité Regional del Valle del Cauca (Colombia).

LÓPEZ, A.S., FERREIRA, H., LLAMOSAS, A. \& ROMEU, A., 1984.- Present Status of Cacao by-Products Utilization in Brazil. Rev. Theobroma, 14 (4): 271-291.

LÓPEZ, R., 2002.- Degradación del suelo: causas, procesos, evaluación e investigación. Centro Interamericano de Desarrollo e Investigación Ambiental y Territorial, Universidad de los Andes, Mérida (Venezuela).

LUNA, M.L., VEGA, C., FRANCO, M.O., VÁSQUEZ, S., TRUJILLO, N., RAMÍREZ, E. \& DENDOOVEN, L., 2002. Actividad microbiana en suelos. Avance y perspectiva, 21: 328-332.

MEDEIROS, A.G., 1977.- Sporulation of Phytophthora palmivora (Butl.) Butl. in relation to epidemiology and chemical control of black pod disease: Ph.D. Thesis, University of California, Riverside (USA).

MEJÍA, L.A. \& ARGÜELLO, O., 2000.- Tecnología para el mejoramiento del sistema de producción de cacao. Publicaciones CORPOICA, Regional 7, Bucaramanga (Colombia).

NAVARRO, M. \& MENDOZA, I., 2009.- Cultivo de cacao en sistemas agroforestales. IPADE, Managua (Nicaragua).

NAVARRO, S. \& NAVARRO, G., 2003.- Química agrícola. El suelo y los elementos químicos esenciales para la vida vegetal. Segunda edición. Ediciones Mundi-Prensa libros, S.A. Madrid (España).

PARRA, D., 1994.- Diagnóstico de enfermedades que afectan el cultivo del cacao en Barlovento y su comportamiento epidemiológico (en) Taller Nacional de Cacao. Resúmenes. Estación Experimental Miranda, Caucagua (Venezuela).

POT., 2012. Plan de Ordenamiento Territorial de Yaguará (Huila). Disponible en: http://yaguara-huila. gov.co/apc-aa-files/63313339363761396435646639323864/documento-de-trabajo-plan-desarrolloyaguara-empresa-para-todos-pag-web_1.pdf

POTREY-PAZOS, A., 2007.- Los hongos en el ecosistema. Agrupación Micológica A Zarrota, Galicia (España).

SADEGHIAN-KHALAJABADI, S., 2012.- Efecto de los cambios en las relaciones de calcio, magnesio y potasio intercambiables en suelos de la zona cafetera colombiana sobre la nutrición del café (Coffea arabica L.) en la etapa de almácigo. Universidad Nacional de Colombia, Medellín (Colombia).

SÁENZ, C.B., 1991.- El cultivo del cacao. Federación de Cacaoteros de Colombia - Editorial Tolaser, Bogotá (Colombia).

SIG-CORPOICA, 2004.- Programa Agroecosistemas. Sistema de Información Georreferenciada-Corporación Colombiana de Investigación Agropecuaria, C.I. Tibaitatá (Colombia).

SILVA, A., PONCE DE LEÓN, J., CARASSA, R. \& REYES, W., 1992.- Efecto de la aplicación de efluentes orgánicos de tambo sobre la producción de verdeos y propiedades fisicoquímicas del suelo. Notas Técnicas. Facultad de Agronomía, Montevideo (Uruguay).

VALENZUELA, J.F., 2012.- El cultivo de cacao. Paquete tecnológico Compañía Nacional de Chocolates S.A.S., Medellín (Colombia).

VERA, D., PÉREZ, H. \& VALENCIA, H., 2002.- Distribución de hongos solubilizadores de fosfatos en dos microhábitats de suelo de dos unidades fisiográficas de Guaviare, Colombia. Acta Biológica Colombiana, 7 (1): 9p.

VERA, M., ROSALES, H. \& UREÑA, N., 2000.- Caracterización físico-química de algunos suelos cacaoteros de la zona sur del lago de Maracaibo. Revista Geográfica Venezolana, 41 (2): 257-270.

ZAPATA, R.D, 2004.- Química de la acidez del suelo. Universidad Nacional de Colombia-Sede Medellín, Medellín (Colombia). 